\title{
Investigation and management of an outbreak of Salmonella Typhimurium DT8 associated with duck eggs, Ireland 2009 to 2011
}

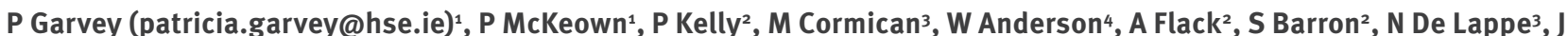

Buckley $^{5}$, C Cosgrove ${ }^{6}$, D Molloy ${ }^{6}$, J O'Connor ${ }^{3}$, P O'Sullivan', J Matthews ${ }^{4}$, M Ward ${ }^{8}$, A Breslin', M B 0'Sullivan ${ }^{10}$, K Kelleher ${ }^{11}$, A McNamara ${ }^{12}$, C Foley-Nolan ${ }^{13}$, H Pelly ${ }^{14}$, F Cloak $^{1}$, Outbreak control team ${ }^{15}$

1. Health Protection Surveillance Centre, Dublin, Ireland

2. Irish Department of Agriculture, Food and the Marine, Dublin, Ireland

3. National Salmonella, Shigella and Listeria Reference Laboratory, Medical Microbiology Department, University Hospital Galway, Galway, Ireland

4. Food Safety Authority of Ireland, Dublin, Ireland

5. Veterinary Department, Cork County Council, Cork, Ireland

6. Health Service Executive, Communicable Disease Unit of the Environmental Health Service, Blanchardstown Dublin, Ireland

7. Department of Public Health, Health Service Executive Mid-West, Department of Public Health, HSE West, Limerick, Ireland

8. Department of Public Health, Health Service Executive East, Dr Steeven's Hospital, Dublin, Irelan

9. Department of Public Health Medicine, Health Service Executive North West, Sligo, Ireland

10. Department of Public Health, Health Service Executive South, Wilton, Cork, Ireland

11. National Office for Health Protection, Health Service Executive Offices, Limerick, Ireland

12. Department of Public Health, Health Service Executive Dublin/Mid-Leinster, Tullamore Co. Offaly, Ireland

13. Food Safety Promotion Board, Cork, Ireland

14. Department of Public Health, Health Service Executive West, Merlin Park Hospital, Galway, Ireland

15. The remaining members of the team are listed at the end of the article

Citation style for this article:

Garvey P, McKeown P, Kelly P, Cormican M, Anderson W, Flack A, Barron S, De Lappe N, Buckley J, Cosgrove C, Molloy D, O’Connor J, O'Sullivan P, Matthews J, Ward M, Breslin A, O'Sullivan MB, Kelleher K, McNamara A, Foley-Nolan C, Pelly H, Cloak F, Outbreak control team. Investigation and management of an outbreak of Salmonella Typhimurium DT8 associated with duck eggs, Ireland 2009 to 2011. Euro Surveill. 2013;18(16):pii=20454. Available online: http://www. eurosurveillance.org/ViewArticle.aspx?Articleld $=20454$

Salmonella Typhimurium DT8 was a very rare cause of human illness in Ireland between 2000 and 2008 , with only four human isolates from three patients being identified. Over a 19-month period between August 2009 and February 2011, 34 confirmed cases and one probable case of Salmonella Typhimurium DT8 were detected, all of which had an MLVA pattern 2-10-NA-12-212 or a closely related pattern. The epidemiological investigations strongly supported a link between illness and exposure to duck eggs. Moreover, $S$. Typhimurium with an MLVA pattern indistinguishable (or closely related) to the isolates from human cases, was identified in $\mathbf{2 2}$ commercial and backyard duck flocks, twelve of which were linked with known human cases. A range of control measures were taken at farm level, and advice was provided to consumers on the hygienic handling and cooking of duck eggs. Although no definitive link was established with a concurrent duck egg-related outbreak of $S$. Typhimurium DT8 in the United Kingdom, it seems likely that the two events were related. It may be appropriate for other countries with a tradition of consuming duck eggs to consider the need for measures to reduce the risk of similar outbreaks.

\section{Introduction}

Salmonella enterica is the second most common cause of bacterial gastroenteritis in most European Union (EU) Member States, including Ireland [1]. The reported annual crude incidence rate for human salmonellosis in Ireland has ranged from 8.1 to 10.8 per 100,000 between 2004 and 2010 (8.4 per 100,000 in 2010). Although $S$. Typhimurium was the most common serotype among indigenous cases of salmonellosis from 2008 and 2010 [2], the DT8 phage type was a very rare cause of illness, with only four isolates from three patients identified between 2000 and 2008. The related S. Typhimurium phage type DT30 is also very rare.

S. Typhimurium DT8 is also uncommon in the rest of Europe [1], but was associated with a small salmonellosis outbreak in Scotland in late 2009 [3] and implicated in sporadic cases of salmonellosis associated with consumption of duck eggs in Germany during the $1990 \mathrm{~s}$ [4]. Contaminated duck eggs have been recognised as a vehicle of Salmonella Typhimurium infection as far back as 1949, when 40 nurses in a London hospital fell ill after eating a lightly cooked pudding prepared with duck eggs [5]. Here we report on the investigation of an outbreak of S. Typhimurium DT8 which occurred in Ireland between August 2009 and May 2011.

\section{Methods}

Outbreak case definition and case finding In this outbreak, a confirmed case was defined as a person with laboratory-confirmed infection with 


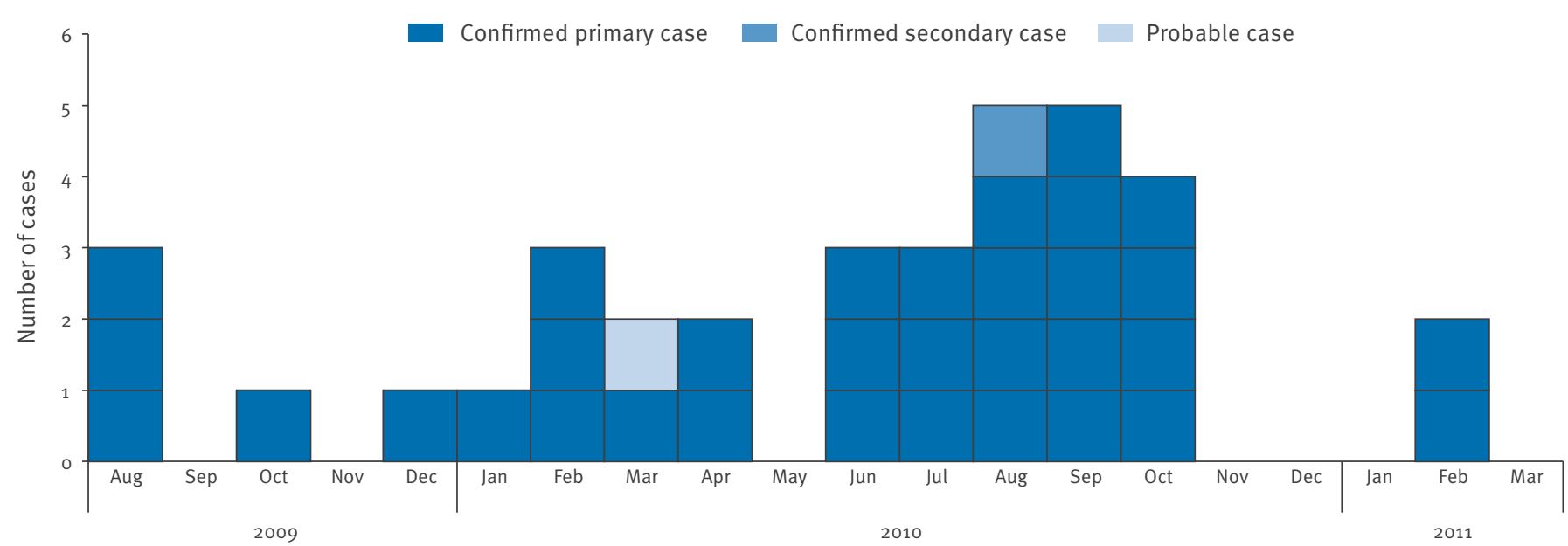

Month and year of onset

Salmonella Typhimurium DT8 (MLVA pattern 2-10-NA12-212 or a closed related pattern) and a date of onset or sample date between 1 August 2009 and 24 May 2011. A closely related pattern was one that differed at one locus or with minor differences at two loci. A probable case was defined as a person with diarrhoea, fever, abdominal pain or vomiting between 1 August 2009 and 24 May 2011 and an epidemiological link (household) to a laboratory-confirmed case. The definition was further refined to exclude one person who had spent their entire incubation period outside of Ireland, and to exclude a laboratory-acquired case.

Confirmed outbreak cases were identified from isolates submitted for typing. Referral of Salmonella isolates by clinical laboratories is voluntary but essentially complete (Martin Cormican NSSLRL, personal communication, April 2010), thus ascertainment of laboratoryconfirmed cases is likely to have been comprehensive. Probable cases were identified among household contacts of confirmed cases during interviews.

\section{Epidemiological investigations}

Demographic, laboratory and exposure information on human cases was gathered. The Epidemic Intelligence Information System (EPIS) of the European Centre for Disease Prevention and Control (ECDC) was used to circulate a request for information on similar cases to colleagues in other EU Member States on 23 April 2010, when a hypothesis began to emerge.

\section{Food and traceback investigations}

Traceback investigations involved multiple agencies to establish the suppliers of duck eggs to those outlets where cases had bought/obtained duck eggs, followed by on-farm testing of environmental samples, including duck faeces, for Salmonella. Forward tracking of ducks from positive farms to secondary farms was also undertaken, with Salmonella testing at secondary farms. Duck farms were classified as 'large commercial' ( $\geq 100$ birds) or 'backyard' ( $(100$ birds) flocks. As the outbreak progressed, all large commercial duck farms were tested. In addition, hygiene and production practices at the duck farms were inspected and the duck egg distribution network was reviewed.

\section{Laboratory typing methods}

All isolates detected were confirmed as S. enterica serotype Typhimurium according to the KauffmannWhyte-Le Minor scheme using slide agglutination (Murex Biotech Ltd., Dartford, United Kingdom, and Sifin Institut, Berlin, Germany) $[6,7]$. Antimicrobial susceptibility testing to a range of antimicrobial agents (ampicillin, chloramphenicol, streptomycin, sulphonamides (8-1024), tetracycline, trimethoprim, naladixic acid, kanamycin, ciprofloxacin, cefpodoxime, gentamicin, ceftazadime and cefotaxime) was determined using the broth dilution method (Sensititre, TREK Diagnostic Systems, East Grinstead, United Kingdom) [8]. The European Committee on Antimicrobial Susceptibility Testing (EUCAST) clinical breakpoints were used for interpretation [9]. Multilocus variable-number tandem repeat analysis (MLVA) was performed according to method of Larrson et al. 2009 [10]. Pulsed-field gel electrophoreses (PFGE) was performed on selected isolates using the PulseNet protocol [11]. 
Reported exposure to and source of duck eggs, Salmonella Typhimurium outbreak, by disease onset, Ireland, 1 August 2009-24 May $2011(\mathrm{n}=35)$

\begin{tabular}{|c|c|c|c|c|c|c|c|}
\hline \multirow[b]{2}{*}{ Month and year } & \multicolumn{4}{|c|}{ Duck egg exposure ${ }^{a}$} & \multirow[b]{2}{*}{$\begin{array}{c}\text { No duck egg } \\
\text { exposure }\end{array}$} & \multirow[b]{2}{*}{$\begin{array}{l}\text { Exposure } \\
\text { history } \\
\text { unknown }\end{array}$} & \multirow[b]{2}{*}{ Total } \\
\hline & $\begin{array}{l}\text { Large } \\
\text { commercial } \\
\text { flock }\end{array}$ & $\begin{array}{c}\text { Backyard flock } \\
\text { selling eggs for } \\
\text { profit }\end{array}$ & $\begin{array}{l}\text { Backyard flock } \\
\text { with eggs for } \\
\text { private use only }\end{array}$ & $\begin{array}{l}\text { Unclassified } \\
\text { source }\end{array}$ & & & \\
\hline Aug 2009 & 0 & 0 & 1 & 1 & 0 & 1 & 3 \\
\hline Sep 2009 & 0 & 0 & 0 & 0 & 0 & 0 & 0 \\
\hline Oct 2009 & 0 & 0 & 0 & 0 & 0 & 1 & 1 \\
\hline Nov 2009 & 0 & 0 & 0 & 0 & 0 & 0 & 0 \\
\hline Dec 2009 & 0 & 0 & 0 & 1 & 0 & 0 & 1 \\
\hline $\operatorname{Jan} 2010$ & 0 & 0 & 1 & 0 & 0 & 0 & 1 \\
\hline Feb 2010 & 2 & 0 & 0 & 1 & 0 & 0 & 3 \\
\hline Mar 2010 & 2 & 0 & 0 & 0 & 0 & 0 & 2 \\
\hline Apr 2010 & 1 & 0 & 0 & 0 & 1 & 0 & 2 \\
\hline May 2010 & 0 & 0 & 0 & 0 & 0 & 0 & 0 \\
\hline Jun 2010 & 0 & 0 & 0 & 0 & 3 & 0 & 3 \\
\hline Jul 2010 & 1 & 0 & 0 & 0 & 2 & 0 & 3 \\
\hline Aug 2010 & 0 & 0 & $4^{b}$ & 0 & 1 & 0 & 5 \\
\hline Sep 2010 & 1 & 2 & 1 & 0 & 0 & 1 & 5 \\
\hline Oct 2010 & 0 & 0 & 2 & 0 & 2 & 0 & 4 \\
\hline Nov 2010 & 0 & 0 & 0 & 0 & 0 & 0 & 0 \\
\hline Dec 2010 & 0 & 0 & 0 & 0 & 0 & 0 & 0 \\
\hline Jan 2011 & 0 & 0 & 0 & 0 & 0 & 0 & 0 \\
\hline Feb 2011 & 0 & 2 & 0 & 0 & 0 & 0 & 2 \\
\hline Total & 7 & 4 & 9 & 3 & 9 & 3 & 35 \\
\hline
\end{tabular}

a Duck flocks are classified either as large commercial flocks ( $\geq 100$ birds) or backyard flocks ( $\$ 100$ birds).

b Secondary case included here along with case from whom they acquired their illness.

\section{Results}

\section{Descriptive epidemiology}

When the outbreak was declared over on 24 May 2011 because no new cases have appeared since the end of February, 34 laboratory-confirmed cases and one probable case have been identified. Cases were distributed across seven of the eight public health administrative areas (HSE areas) in Ireland. The earliest date of onset was 14 August 2009, while the last was 27 February 2011 (Figure). The shape of the outbreak curve is consistent with an intermittent-source outbreak. Notably, fewer cases were reported during winter periods.

Within the outbreak, there were five family clusters of two cases each. In one family, a young infant was considered a secondary case. The cases' ages ranged from less than one year to 88 years (median: 42 years) and male cases predominated (23 male versus 12 female cases).

The clinical symptoms of the cases were diarrhoea (28/29), fever (19/23), abdominal pain (19/25), and nausea $(16 / 22)$, with less frequent reports of blood in stools (13/24), vomiting (14/26) and headache (4/14). Symptom duration ranged from one to 21 days (median: 7 days), based on information from 21 cases. Most cases (18/33) were admitted to hospital. One of them died, but the death was not attributed to salmonellosis.

Those EU Member States who responded to the initial inquiry in April 2010 indicated at the time that Salmonella Typhimurium DT8 was an uncommon cause of human illness and that they had no increase in case numbers. However, Norwegian colleagues reported that there were isolations of similar but not indistinguishable MLVA previously from larger birds, but there were no reports of recent isolations from ducks. In July 2010, colleagues from the former Health Protection Agency in the United Kingdom (UK) informed the Irish Health Protection Surveillance Centre (HPSC) of an excess of S. Typhimurium DT8 cases in England, Wales and Northern Ireland that began in the summer of 2010 [12].

\section{Hypothesis generation}

Under Infectious Diseases (Amendment) Regulations 2011 (S.I. No. 452 of 2011), human salmonellosis is notifiable in Ireland, and epidemiological investigation 
of clusters is routine, the size threshold being lowest for uncommon strains. In August 2009, the reporting of three cases of a salmonella variant previously reported as rare in Ireland prompted an epidemiological investigation. Exposure data obtained on two of the three reported cases using a standard national Salmonella trawling questionnaire indicated that both had consumed duck eggs, although from different sources, including one backyard flock from which duck eggs were not sold to the public. The third case could not be contacted.

All three isolates available at that time, as well as two further human isolates identified later in 2009, had the MLVA pattern 2-10-NA-12-212 or a closely related pattern, suggesting a common source. The MLVA pattern of these isolates differed at multiple loci from that observed with the three previous human S. Typhimurium DT8 from Ireland isolated between 2000 and 2008.

On detection of a second cluster of cases beginning late January 2010, national salmonella trawling questionnaires were again applied. Of seven confirmed and one probable case with onset dates between January and April 2010, seven reported consumption of/exposure to duck eggs. Although comparison of consumption data for the population as a whole was not possible, this exposure was believed to be relatively uncommon in the general population. Therefore ducks eggs were considered the likely source of the outbreak.

\section{Exposure history}

When the outbreak was declared over, duck egg exposure was reported for 22 of 31 primary cases with known exposure histories. An additional case classified as a secondary case was linked to a confirmed case who had consumed duck eggs. Cases reported obtaining duck eggs from multiple sources including non-commercial sources, suggesting that infection was probably not related to a single duck flock. Earlier cases were exposed to duck eggs from both larger commercial and backyard sources, while later cases were more likely to have consumed duck eggs from backyard flocks (Table 1).

\section{Traceback investigations}

The duck egg trade proved to be highly complex. The eggs are often supplied from one flock to several retailers, and retailers often source duck eggs from multiple suppliers. This necessitated forward- as well as back-tracing investigations when $S$. Typhimurium was detected on farms. Unlike all hen eggs sold at retail level in Ireland, which must be sourced from an egg packing centre registered with the Irish Department of Agriculture, Food and the Marine (DAFM), retailers source duck eggs directly from producers. In addition, eggs from backyard flocks were not marked, making it difficult to trace back to source.
TABLE 2

Duck flocks tested positive for Salmonella Typhimurium during the outbreak investigation Ireland, 1 August 2009-24 May $2011(n=25)$

\begin{tabular}{|l|c|c|c|}
\hline & $\begin{array}{c}\text { Large } \\
\text { commercial } \\
\text { flock }\end{array}$ & $\begin{array}{c}\text { Backyard } \\
\text { flock selling } \\
\text { eggs for profit }\end{array}$ & $\begin{array}{c}\text { Backyard flock } \\
\text { with eggs for } \\
\text { private use only }\end{array}$ \\
\hline $\begin{array}{l}\text { Flocks associated } \\
\text { with human cases }\end{array}$ & 6 & 3 & 3 \\
\hline $\begin{array}{l}\text { Flocks not } \\
\text { associated with } \\
\text { human cases but } \\
\text { tested as part of } \\
\text { investigation }\end{array}$ & $12^{\text {a }}$ & 1 & 0 \\
\hline Total & $\mathbf{1 8}^{\text {a }}$ & $\mathbf{4}$ & $\mathbf{3}$ \\
\hline
\end{tabular}

All S. Typhimurium were either DT8 or DT30 unless indicated otherwise by footnotes.

a includes one flock each positive for DT56var, DT41 and DT120(low).

Initial investigations focused on larger commercial duck farms directly or indirectly linked with outbreak cases, but were expanded to include all large commercial duck farms and a number of backyard flocks selling for profit. Between March 2010 and May 2011, 64 farms had been inspected and sampled, with $S$. Typhimurium isolated from 22 of these (Table 2). Of these 22, nine farms were linked to eleven human cases. In addition, three backyard flocks (linked with another four human cases) were also found positive for salmonella (Table 2), making it 25 positive flocks in total. Isolates from 22 of these $25 \mathrm{~S}$. Typhimurium-positive duck egg farms were typed as DT8 or DT30 with MLVA pattern 2-10NA-12-212 or a related pattern. A further three commercial flocks not linked to human DT8 cases were positive for S. Typhimurium phage types DT56var, DT41 or DT120(low) (Table 2).

One of two duckling hatcheries in Ireland was positive for S. Typhimurium (DT56var) but not for the outbreak strain. This hatchery supplied three of the farms positive for Salmonella, but two of those farms also received chicks from other sources. Duck farm samples taken for testing did not include duck eggs; in one instance, eggs were tested from a supplier, but no eggs were left over for testing from case households. While poultry feed was not specifically sampled during this outbreak, feed from licensed poultry feed mills is analysed routinely by DAFM as part of their procedures.

\section{Strain typing}

MLVA analyses of isolates from the 34 laboratory-confirmed human cases within the outbreak showed that 20 had the MLVA pattern 2-10-NA-12-212. The remainder had patterns that differed at one locus or showed minor differences at two loci (Table 3). All but two isolates were susceptible to all antimicrobial agents 
tested. Similarly, all DT8/DT30 isolates recovered during the investigation of egg-laying duck farms had the MLVA pattern 2-10-NA-12-212 (or a pattern which differed at a single locus).

PFGE was performed on 18 isolates (selected to represent different sources (human/animal, MLVA profiles and antibiograms). In all, 13 human and two duck DT8 isolates were examined. These were indistinguishable from each other and from a pattern previously designated as STYMXB.0330 on the PulseNet Europe PFGE database..

\section{Control measures}

A variety of control measures were applied at different points during the investigation, as evidence for likely sources of infection became available. Some were aimed at farms and others at consumers.

\section{Farm level control measures}

Movement of birds was immediately restricted and duck egg sales suspended on all farms from which S. Typhimurium was isolated. Most flocks were culled voluntarily. Farms were advised that duck houses should be cleansed and disinfected, and lime applied to pasture. Environmental swabs were recommended to confirm absence of Salmonella after cleansing and disinfection of the infected premises to ensure that no infection remained before new stock was introduced. Sourcing of new birds from parent flocks with documented negative tests for Salmonella was also recommended.

In summer 2010, a code of practice was issued to commercial duck egg producers incorporating recommendations on traceability, disease control, biosecurity and testing [13]. In October 2010, additional guidelines were devised for backyard producers of small quantities of duck eggs and circulated to more than 3,000 people registered as keeping ducks [14]. In November 2010, new legislation (S.I. No. 565 of 2010), the 'Diseases of Animals Act 1966 (Control of Salmonella in Ducks) Order 2010' [15] set down a legal basis for the control of salmonellosis in ducks and duck eggs in Ireland. This legislation applies to all duck flocks, regardless of size, from which duck eggs are traded for profit [15].

\section{Advice to consumers}

A series of press releases was issued to the public by the Food Safety Authority of Ireland (FSAI) and HPSC (on 23 April 2010, 27 April 2010, 29 July 2010 and 14 September 2010) advising consumers that duck eggs should be thoroughly cooked and that good hygiene practices should be followed to avoid cross contamination from duck eggs [16-19]. The risk from eating raw cake batter containing duck eggs was highlighted [19]. In April 2010, Environmental Health Officers distributed a point-of-sale warning notice for public display to all duck egg retailers [20]. Similar notices were distributed to nursing homes and hospitals. In November
TABLE 3

Multilocus variable-number tandem repeat analysis and antimicrobial agent sensitivity patterns of isolates for confirmed human outbreak cases $(n=34)$

\begin{tabular}{|l|c|c|c|c|}
\hline \multirow{2}{*}{ MLVA pattern } & \multicolumn{4}{|c|}{ Resistance to antimicrobial agents } \\
\cline { 2 - 5 } & None & A & ASuTm & Total \\
\hline 2-10-NA-12-212 & 21 & 0 & 1 & 22 \\
\hline 2-10-NA-12-NA & 1 & 0 & 0 & 1 \\
\hline 2-12-NA-12-212 & 1 & 0 & 0 & 1 \\
\hline 2-9-NA-11-212 & 3 & 0 & 0 & 3 \\
\hline 2-9-NA-12-212 & 3 & 1 & 0 & 4 \\
\hline 2-9-NA-13-212 & 2 & 0 & 0 & 2 \\
\hline 3-10-NA-12-212 & 1 & 0 & 0 & 1 \\
\hline Total & 32 & 1 & 1 & 34 \\
\hline
\end{tabular}

A: ampicillin; MLVA: multilocus variable-number tandem repeat analysis; Su: sulfadiazine; Tm: trimethoprim.

EUCAST clinical breakpoints were used.

2010, a public information campaign (including an information postcard for distribution at point of sale) was undertaken by Safefood, an agency with responsibility for promotion of food safety messages to consumers [21].

\section{Discussion}

This outbreak-associated strain of $S$. Typhimurium represented more than $12 \%(28 / 225)$ of the confirmed salmonellosis cases in Ireland in 2010 that were not travel-related. The link between illness and duck eggs was supported by descriptive epidemiology and by microbiological evidence. Given the strength of evidence, an analytical epidemiological study was deemed unnecessary.

The PFGE pattern was indistinguishable from the strain implicated in the summer 2010 outbreak in England and Northern Ireland, and from an isolate identified in Scotland in 2009 [3,12]. Colleagues at the Centers for Disease Control and Prevention in the United States (Peter Gerner-Smidt, personal communication, September 2010) reported that the outbreak PFGE profile (known as JPXX01.1689 in the Pulsenet USA database) was rare in the United States and had not been seen since August 2008. This PFGE profile was also identified previously in China (known there as JPXXo1. CNo030) but was not identified among human cases there in 2010 (Biao Kan, personal communication, September 2010).

The variety of typing methods used facilitated investigation and management of the outbreak. Serotyping and phage typing allowed for rapid preliminary identification of outbreak-related cases. MLVA showed that the initial isolates were indistinguishable from 
each other but distinguishable from older isolates and helped to confirm that we were dealing with a new phenomenon. That some diversity in MLVA types was observed as transmission continued is not surprising in an extended outbreak, given the mutability of MLVA loci. The fact that all outbreak isolates were indistinguishable by PFGE is consistent with the greater stability of PFGE patterns over time and helped to support our view that the degree of tolerance of MLVA variation that was accepted within the definition of the outbreak strain was appropriate.

In Ireland, the duck egg industry is very small compared with the chicken egg industry. It is comprised of 30 to 40 larger commercial businesses and an estimated 3,000 backyard flocks, some of whom sell duck eggs to the public. Production is largely outdoors, and duck eggs represent less than $1 \%$ of table egg sales (Patricia Kelly DAFM, personal communication, April 2010). Although duck eggs are a traditional food in Ireland, no association with human salmonellosis had been documented before 2009. There is no reason to believe that there was an abrupt increase in duck egg consumption or change in the pattern of consumption or methods of preparation in recent years.

S. Typhimurium DT8 has been reported elsewhere as associated with ducks for decades [4]. We are not aware of studies of Salmonella in egg-laying duck flocks in Ireland that predate this outbreak and can therefore not say that laying duck flocks were free of Salmonella before this outbreak. However, given no apparent change in consumption patterns, it seems likely that the cause of this outbreak may be related to recent introduction into Ireland of a Salmonella strain with considerable pathogenic potential. The similarity of the isolates by MLVA (which is discriminatory for DT8 isolates) also suggests recent and rapid dissemination from a common source.

The source of contamination has not been definitively established. Introduction through contact with wild birds is possible. However, the published description of a similar outbreak of $S$. Typhimurium DT8 that occurred in England and Northern Ireland around the same time, and the documented trade of ducklings from UK hatcheries to Ireland, means that a UK source of contamination related to trade in ducklings is plausible [12].

There are few reported outbreaks associated with S. Typhimurium DT8, although in Germany sporadic infections with $S$. Typhimurium DT8 have been associated with the consumption of raw and undercooked duck eggs [3,4]. During the early 1990s, S. Typhimurium DT8 was also the most common $S$. Typhimurium phage type associated with disease in ducks in Germany, and it was suggested that DT8 (and another S. Typhimurium phage type DT46) might be host-adapted to ducks [4]. In the UK, the Department for Environment, Food and Rural Affairs has reported that, while $S$. Typhimurium accounted for a minority of isolates from ducks during
2005 and 2006, most of these were DT8 [22]. In France, a study by Lailler et al. also reported a close association between this phage type and ducks [23].

Only 22 of 31 of primary cases within the outbreak could be explained by documented consumption of/ exposure to duck eggs. It is not uncommon in foodborne outbreaks to be unable to link all cases with the source identified. This may be explained by failure to recall exposure, unknowing consumption of duck egg, unknowing contact with an infected person, or by some of the cases being caused by alternative sources.

Because faecal contamination of duck eggs can occur, it is the practice to wash the duck eggs prior to sale (Patricia Kelly DAFM, personal communication, July 2010). Examination of a batch of implicated duck eggs after disinfection of the shell failed to detect $S$. Tyhimurium inside the eggs. This is consistent with the suggestion that $S$. Typhimurium is associated primarily with the shell, although it has been proposed that washing of chicken eggs can lead to Salmonella entering the egg via the pores in the shell [24].

From January to May 2011, there were only two new human cases of DT8 infection, a dramatic decrease from the 2010 levels. We declared the outbreak over in May 2011 assuming the period of high intensity transmission had passed, however we anticipated that occasional cases might still be reported for a prolonged period if the strain persisted in backyard flocks. In fact only six further cases occurred in the remaining seven months of 2011, and investigation of duck egg sources associated with these cases continued through 2011. The legislation and good practice guidance introduced in connection with this outbreak was key to the ongoing control of the risk of salmonellosis associated with consumption of duck eggs. As there has been only a single non-travel-related human isolate of $S$. Typhimurium DT8 to date in 2012 (MLVA 2-9-NA-12-212), it appears that the measures taken have had a sustained impact in protecting public health.

From an international perspective, this outbreak highlights the vulnerability of animal food production systems that are outside the scope of regulatory control to the emergence of new pathogenic variants, and the effectiveness of a vigorous multi-agency response to the protection of human health. It may be appropriate for other countries with a tradition of consumption of duck eggs to consider the need for measures to reduce the risk of similar outbreaks and for the EU to consider whether any changes are required to EU regulations in this regard. 


\section{Acknowledgements}

The authors wish to acknowledge the contribution of the Food and Waterborne Disease (FWD) team at ECDC, colleagues in the ECDC FWD Network, Consultant Microbiologists, Medical Scientists, Public Health Physicians, Surveillance Scientists, and Environmental Health Officers around Ireland, other staff at HPSC, DAFM, NSSLRLG, FSAI, Cork County Council Veterinary Food Safety Laboratory, and the Central Veterinary Research Laboratory, during the course of the investigation. We also wish to thank the former Health Protection Agency in the UK for sharing information on the concurrent $S$. Typhimurium DT8 outbreak in the UK, and Health Protection Scotland colleagues for sharing Salmonella strains.

\section{Conflict of interests}

None declared

\section{Members of the cutbreak control team}

S Jackson, D O Mahony, D Guina-Dornan, D Crowley, L Thornton, A Reilly, D Igoe, F O’Neill, A Sheehan, M Mulcahy, G McGrane.

\section{References}

1. European Centre for Disease Prevention and Control (ECDC) and the European Food Safety Authority (EFSA). The Community summary report on trends and sources of zoonoses, zoonotic agents and food-borne outbreaks in the European Union in 2008. Stockholm, Parma: ECDC, EFSA; 2010. Available from http://www.efsa.europa.eu/en/efsajournal/doc/1496.pdf

2. Health Protection Surveillance Centre (HPSC). Annual report 2009. Dublin: HPSC; 2010. ISSN 1649-0436. Available from: http://www.hpsc.ie/hpsc/AboutHPSC/AnnualReports/ File,4751,en.pdf

3. Smith-Palmer A, Brownlie S, Cowden J. Gastro-intestinal and foodborne infections General outbreaks of infectious intestinal disease reported to HPS during the third quarter of 2008 . HPS Weekly Report. 2009;43(2009/49):460-1. Available from: http://www.hps.scot.nhs.uk/documents/ewr/pdf2009/0949. pdf PMid:11953356 PMCid:127920

4. Rabsch W, Andrews HL, Kingsley RA, Prager R, Tschäpe H, Adams LG, et al. Salmonella enterica serotype Typhimurium and its host-adapted variants. Infect Immun. 2002;70(5):224955. http://dx.doi.org/10.1128/IAl.70.5.2249-2255.2002 PMid:11953356 PMCid:127920

5. Garrod LP, Mcllroy MB. Hospital outbreak of enteritis due to duck eggs. Br Med J. 1949;2(4639):1259-61. http://dx.doi. org/10.1136/bmj.2.4639.1259

6. Grimont PA, Weill FX. Antigenic formulae of the Salmonella serovars. 9th edition. Paris: World Health Organization Collaborating Centre for Reference and Research on Salmonella, Pasteur Institute; 2007. Available from: http:// www.pasteur.fr/ip/portal/action/WebdriveActionEvent/ oid/015-000036-089

7. Anderson ES, Ward LR, Saxe MJ, de Sa JD. Bacteriophagetyping designations of Salmonella Typhimurium. J Hyg (Lond). 1977;78(2):297-300. http://dx.doi.org/10.1017/ So022172400056187

8. Wikler MA, Cockerill FR, Bush K, Dudley MN, Eliopoulos GM, Hardy DJ, et al. Methods for dilution antimicrobial susceptibility tests for bacteria that grow aerobically. Approved standard. 8th Edition. Clinical and Laboratory Standards Institute (CLSI) document Mo7-A8 (ISBN 1-56238 689-1). Wayne: CLSI; 2009. Available from: http://www.scribd. com/doc/89642226/CSLI-2009

9. European Committee on Antimicrobial Susceptibility Testing (EUCAST). Breakpoint tables for interpretation of MICS and zone diameters. Version 2.0. Basel: European Society of Clinical Microbiology and Infectious Diseases; 2012. Available from: http://www.eucast.org/fileadmin/src/ media/PDFs/EUCAST_files/Breakpoint_tables/Breakpoint_ table_v_2.0_120221.p df

10. Larsson JT, Torpdahl M, Petersen RF, Sørensen G, Lindstedt BA, Nielsen EM. Development of a new nomenclature for Salmonella Typhimurium multilocus variable number of tandem repeats analysis (MLVA). Euro Surveill. 14(15): pii=19174.
Available from: http://www.eurosurveillance.org/ViewArticle. aspx?Articleld=19174 PMid:16602980 PMid:21470442

11. Ribot EM, Fair MA, Gautom R, Cameron DN, Hunter SB, Swaminathan B, et al. Standardization of pulsed-field gel electrophoresis protocols for the subtyping of Escherichia coli 0157:H7, Salmonella, and Shigella for PulseNet. Foodborne Pathog Dis. 2006;3(1):59-67. http://dx.doi.org/10.1089/fpd.2006.3.59 PMid:16602980

12. Noble DJ, Lane C, Little CL, Davies R, De Pinna E, Larkin L, et al. Revival of an old problem: an increase in Salmonella enterica serovar Typhimurium definitive phage type 8 infections in 2010 in England and Northern Ireland linked to duck eggs. Epidemiol Infect. 2012;140(1):146-9. http://dx.doi.org/10.1017/ So950268811000586 PMid:21470442

13. Department of Agriculture, Food and the Marine (DAFM). Code of practice for duck table egg producers. Dublin: DAFM; 2010. Available from: http://www.agriculture.gov.ie/media/ migration/farmingsectors/poultry/DuckEggsCOPAug151010.pdf

14. Department of Agriculture, Food and the Marine (DAFM). Guidelines for producers of small quantities of duck eggs (backyard flocks). Dublin: DAFM; 2010. Available from: http://www.fsai.ie/uploadedFiles/Food_Businesses/ Topics_of_Interest_to_Food_Businesses/Guidance $\% 20$ for $\% 20$ producers $\% 200 \mathrm{f} \%$ 20small\%20quantities $\% 200 \mathrm{f} \% 20 \mathrm{duck} \% 20$ eggs $\% 20 \% 20$ Final\%20\%2013\%20Sept\%2010.pdf

15. Department of Agriculture, Food and the Marine (DAFM). The diseases of animals act 1966 (Control of Salmonella in ducks) order 2010 (S.I. No. 565 of 2010). Dublin: DAFM; 2010. Available from: http://www.agriculture.gov.ie/media/migration/ legislation/statutoryinstruments2010/SI5652010.pdf

16. Food Safety Authority of Ireland (FSAI). FSAI investigating Salmonella outbreak linked to duck eggs. Dublin: FSAI; 2010. Available from: http://www.fsai.ie/news_centre/press_ releases/23042010.html

17. Food Safety Authority of Ireland (FSAI). FSAI reiterates advice on safe consumption of duck eggs. Dublin: FSAI; 2010. Available from: http://www.fsai.ie/news_centre/press_ releases/29072010.html

18. Food Safety Authority of Ireland (FSAI). Largest outbreak in recent years linked to Salmonella in duck eggs. Dublin: FSAI; 2010. Available from: http://www.fsai.ie/14092010.html

19. Health Protection Surveillance Centre (HPSC). 'Don't lick spoon' when cooking or baking with duck eggs warns HPSC as children fall ill with salmonella. Dublin: HPSC; 2010. Available from: http://www.hpsc.ie/hpsc/A-Z/Gastroenteric/ Salmonellosis/News/MainBody,4289,en.html

20. Food Safety Authority of Ireland (FSAI). Consumer advice on the safe usage of duck eggs. Dublin: FSAI; 2010. Available from: http://www.fsai.ie/uploadedFiles/News_Centre/ News/News_Listing/Duck\%20eggs\%2oupdated\%20 pointofsalenotice(1).pdf

21. Stay safe with duck eggs. Postcard. Available from: Cork: Safefood: 2010. http://www.safefood.eu/Publications/ Consumer-info/Stay-safe-with-duck-eggs.aspx

22. Veterinary Laboratories Agency.Salmonella in Livestock Production in GB: 2008 Report accessed at Available from: http://www.defra.gov.uk/ahvla-en/category/publications/ disease-surv/salmonella-live-prod/

23. Lailler R, Grimont F, Jones $Y$, Sanders P, Brisabois A. Subtyping of Salmonella typhimurium by pulsed-field gel electrophoresis and comparisons with phage types and resistance types. Pathol Biol (Paris). 2002 Jul;50(6):361-8. http://dx.doi.org/10.1016/S0369-8114(02)00321-8

24. EFSA. Opinion of the Scientific Panel on Biological Hazards on the request from the Commission related to the Microbiological Risks on Washing of Table Eggs. The EFSA Journal (2005), 269, 1-39. 